\title{
Metal-on-Metal Total Hip Arthroplasty Associated with Adverse Local Tissue Reaction and Pseudoaneurysm of the Superior Gluteal Artery: A Case Report and Literature Review
}

\author{
Amit Shah ${ }^{1}$ Rajesh Botchu ${ }^{1}$ David Dunlop ${ }^{2}$ A. Mark Davies ${ }^{1}$ Steven L. James ${ }^{1}$ \\ ${ }^{1}$ Department of Musculoskeletal Radiology, Royal Orthopaedic \\ Hospital, Birmingham, United Kingdom \\ 2 Department of Orthopaedics, Royal Orthopaedic Hospital, \\ Birmingham, United Kingdom \\ Address for correspondence Amit Shah, FRCR, Royal Orthopaedic \\ Hospital NHS Foundation Trust, Birmingham, United Kingdom \\ (e-mail: doctigs@gmail.com).
}

Surg J 2016;2:e113-e118.

\begin{abstract}
Keywords

- metal-on-metal hip arthroplasty

- adverse local tissue reaction

- pseudotumor

- pseudoaneurysm

- superior gluteal artery

Adverse local tissue reaction (ALTR) and pseudoaneurysm formation are rare but known complications following metal-on-metal hip total hip arthroplasty (THA). We report the first known case in the English literature of a concurrent unilateral ALTR and pseudoaneurysm of the superior gluteal artery in the same patient. Following minimal rise in serum metal ions, an ultrasound of the right hip demonstrated an avascular solid/cystic lesion anterolaterally in keeping with an ALTR. More posterolaterally, a second discrete thick-walled cystic lesion was identified. Doppler interrogation demonstrated a "yin yang" pattern suggestive of a pseudoaneurysm. Magnetic resonance imaging confirmed the presence of an anterolateral periarticular lesion with a second discrete lesion within the gluteus medius. Subsequent computed tomography angiography confirmed the presence of arterial contrast blush within the posterior gluteal lesion adjacent to the superior gluteal artery. The patient remains asymptomatic and is being managed conservatively. We review the imaging characteristics of ALTR and pseudoaneurysm occurring post-THA. When a complex solid/cystic lesion is encountered in a patient with a THA, radiologists must ensure that the lesion is interrogated with color Doppler to confidently distinguish a pseudotumor from a pseudoaneurysm. This information is vital to the surgeon to avoid unexpected hemorrhage if revision joint replacement surgery is being contemplated.
\end{abstract}

Hip arthroplasty is a common procedure, with nearly 70,000 operations in the United Kingdom in 2014..$^{1}$ Traditional metal-on-polyethylene (MoP) components generate particulate debris, leading to an inflammatory response and resulting in osteolysis and aseptic loosening. To overcome this, metal-on-metal (MoM) devices have increased in popularity, especially in young patients, with the aim of potentially improving wear rates compared with MoP implants. ${ }^{2}$ There are several potential complications including postoperative

received

May 30, 2016 accepted after revision October 3, 2016
DOI http://dx.doi.org/ 10.1055/s-0036-1593855. ISSN 2378-5128. joint effusion, iliopsoas bursitis, tendinitis or impingement, and gluteal tendinopathy. Two rare complications include the formation of a pseudotumor or adverse local tissue reaction (ALTR) and pseudoaneurysm.

We present a case of an asymptomatic patient with a MoM total hip arthroplasty (THA) with an ALTR and pseudoaneurysm of the superior gluteal artery found incidentally during ultrasound assessment for raised serum metal ions. To the best of our knowledge, this is the first reported case in the
Copyright $\odot 2016$ by Thieme Medical Publishers, Inc., 333 Seventh Avenue, New York, NY 10001, USA. Tel: +1(212) 584-4662.
License terms

(요 (1) $\Theta \circledast$ 
English literature of two rare post-THA complications occurring unilaterally and concurrently in the same patient.

\section{Case Report}

A 71-year-old woman underwent a left MoM Birmingham hip resurface (BHR) procedure in 2005 and subsequently had a MoM THA on the right in 2008. The left BHR was revised to a MoM THA in 2012 after worsening of left hip pain. She was monitored annually with serum metal ions and hip radiographs. Her baseline serum cobalt was $158 \mathrm{nmol} / \mathrm{L}$ and serum chromium was $119 \mathrm{nmol} / \mathrm{L}$. The Medicines and Healthcare Products Regulatory Agency reference threshold for serum chromium was $134 \mathrm{nmol} / \mathrm{L}$ and for serum cobalt was 119 nmol/L. Because she was asymptomatic, a clinical decision was made to monitor serum metals ion levels and to obtain imaging if levels remained high. During clinical review in 2014 , the patient reported very occasional discomfort on the right, after strenuous activity, and remained asymptomatic on the left. Clinical examination was unremarkable. Repeat serum ion levels rose slightly, and therefore a radiograph and an ultrasound were requested to assess the right hip. The radiograph demonstrated bilateral THAs in situ but was otherwise unremarkable (-Fig. 1). The ultrasound demonstrated a large joint effusion with synovitis and an anterior periarticular cystic lesion with no internal vascularity ( $\mathbf{- F i g . 2 a}$ and $\mathbf{b}$ ). The collection extended into the iliopsoas bursa ( $\mathbf{- F i g . ~ 2 c}$ and d). Further posterolaterally, there was a thick-walled fluid collection ( - Fig. 3a), separate to the anterolateral collection. Doppler interrogation revealed internal flow in a "yin yang" pattern, highly suggestive of a pseudoaneurysm (-Fig. 3b). Magnetic resonance imaging (MRI) confirmed the large ALTR related to the THA and a second discrete gluteal fusiform soft tissue mass ( $\mathbf{F i g . 4}$ ). The lesion demonstrated hypointense signal internally, on all sequences, suggestive of turbulent flow. Subsequent computed tomography (CT) angiography confirmed arterial contrast blush of the fusiform mass in the right buttock in keeping with a

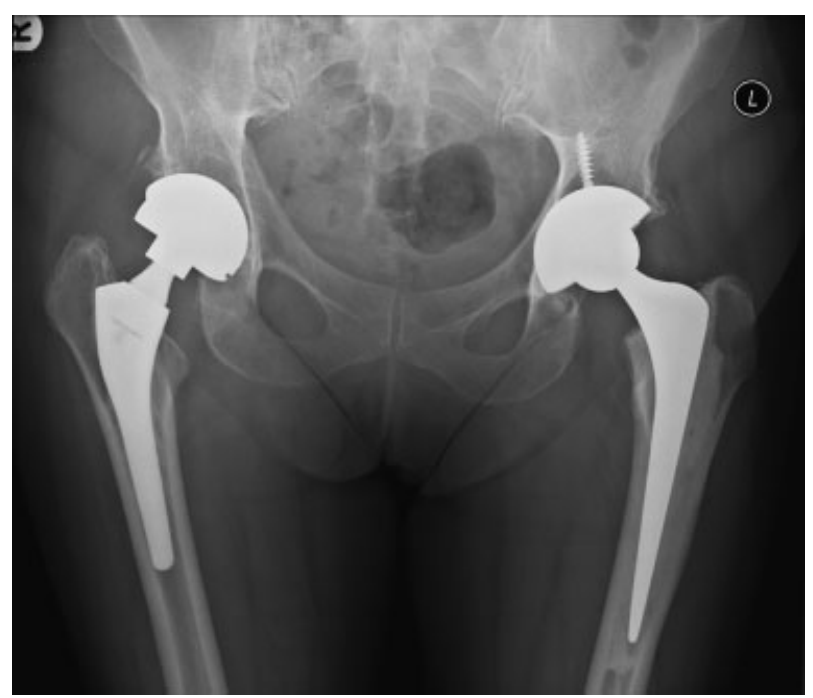

Fig. 1 Anteroposterior radiograph demonstrating bilateral total hip arthroplasties with no adverse features. pseudoaneurysm (-Fig. 5). A neck to its parent vessel could not be identified but was in the territory of the superior gluteal artery. The patient has elected for conservative management because she remains asymptomatic and is being clinically followed.

\section{Discussion}

\section{ALTR/Pseudotumor}

Although the wear rate is lower with MoM devices, ${ }^{3}$ MoM prostheses release metal nanoparticles and ions into the body. ${ }^{4,5}$ The resultant inflammatory response leads to the development of a benign sterile inflammatory soft tissue mass. Particulate debris is detrimental to the durability of MoP implants; so too is an ALTR, which can have drastic effects on the MoM implant and make revision surgery difficult. The reported incidence of ALTR following MoM THA is between 0 and $6.5 \%{ }^{6}$ Pseudotumors, metal hypersensitivity, aseptic lymphocyte-dominated vasculitis-associated lesions, adverse local tissue reactions, and adverse reaction to metal debris are all terms that have been used to describe this rare complication. ${ }^{7}$

The commonest ions released from MoM alloy implants are cobalt (Co) and chromium (Cr). In 2010, the UK Medicines and Healthcare Products Regulatory Agency released a Medical Device Alert in response to the increasing number of revision surgeries for ALTR. ${ }^{8}$ Recommendations included regular clinical follow-up, investigation of those patients with painful MoM arthroplasties, and regular measurement of serum $\mathrm{Co}$ and $\mathrm{Cr}$ ion levels. Imaging was emphasized for those patients with two separate serum metal ion levels above serum $\mathrm{Cr}$ of $134 \mathrm{nmol} / \mathrm{L}$ and Co of $119 \mathrm{nmol} / \mathrm{L}$. Of note, Fang and coworkers concluded that serum metal ion measurements were not on their own sufficiently accurate for monitoring the presence of a pseudotumor in asymptomatic patients. ${ }^{9}$ Thus, patients need to be assessed clinically, biochemically, and radiologically to identify an ALTR.

ALTR can present months to years after surgery, is commoner in females and in patients under 40 years of age, and usually involves both hips in the case of bilateral THAs. ${ }^{10}$ Patients can present with hip pain, spontaneous dislocation, neurologic symptoms, or palpable masses. ${ }^{11}$ It is well recognized that an ALTR can be identified in asymptomatic patients on ultrasound and MRI, as was seen in our patient. ${ }^{12}$ The pathogenesis of an ALTR is unclear but is initiated by the release of metal ions due to excessive wear of the cobaltchrome prosthesis leading to an inflammatory response. Two distinct histopathologic observations have been made, one of predominant macrophage infiltration with little necrosis and one of a predominantly lymphocyte-mediated response with necrosis termed aseptic lymphocyte-dominated vasculitis-associated lesion, ${ }^{13-16}$ which is thought to represent a delayed type IV hypersensitivity reaction. ${ }^{15}$

Radiographs of ALTR are usually normal (-Fig. 1) and are performed to assess the prosthesis and exclude loosening or periprosthetic fracture. A subtle but recognizable radiographic finding is resorption of the calcar femorale, but this finding does not reflect extensive soft tissue changes. ${ }^{17}$ ALTRs are 


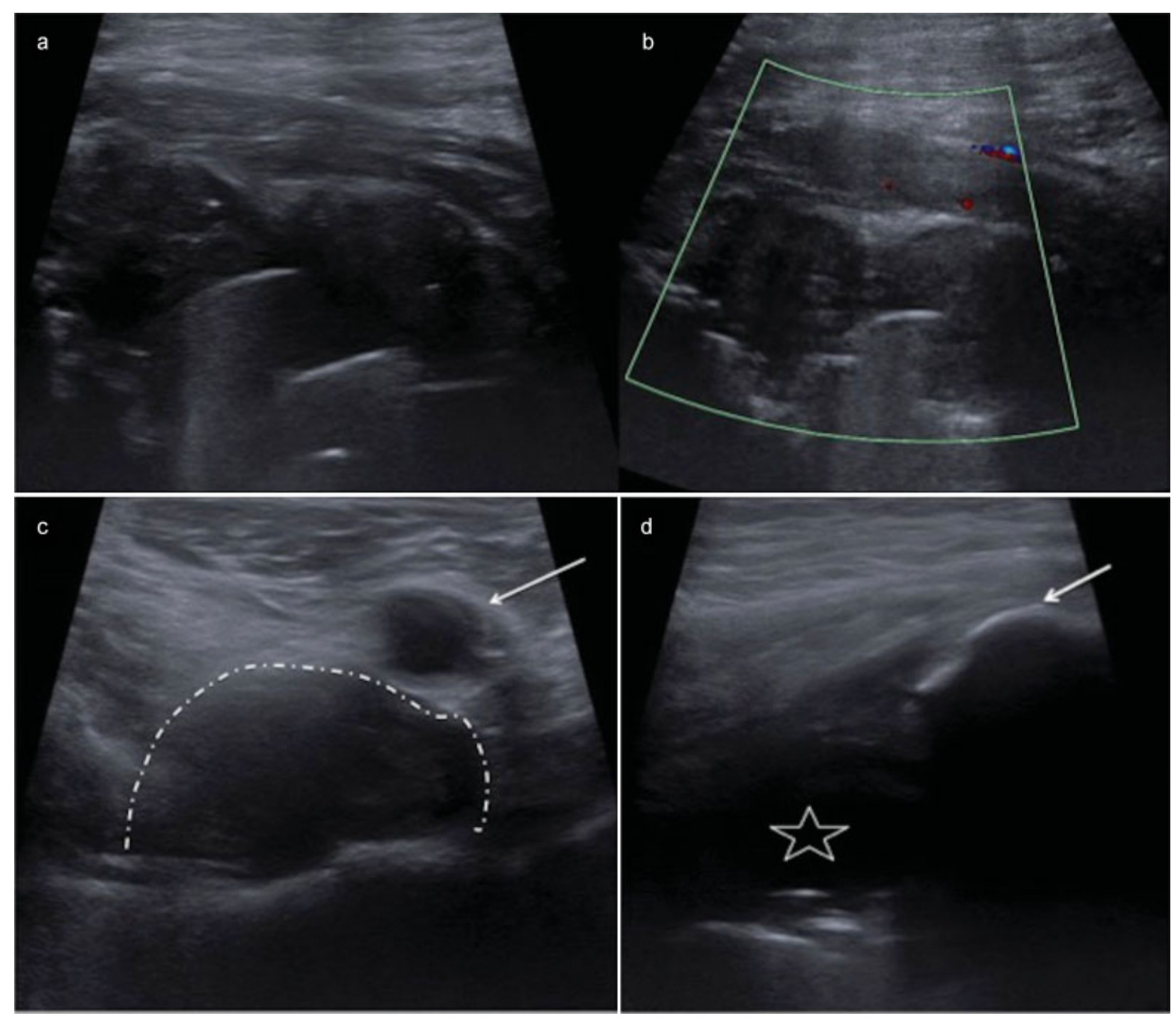

Fig. 2 Longitudinal ultrasound image (a) of the anterior right hip joint demonstrating a mixed echogenic solid/cystic mass. Longitudinal ultrasound Doppler image (b) confirms a lack of vascularity. The transverse ultrasound image (c) confirms extensions of this fluid lesion into the iliopsoas bursa (dotted curve). The white arrow indicates the common femoral artery. Longitudinal ultrasound image (d) demonstrates fluid collection (white star) extension laterally (white arrow indicates the greater trochanter). Appearances are in keeping with an adverse local tissue reaction in a patient with a metal-on-metal hip arthroplasty and raised serum metal ions.

better appreciated on ultrasound, CT, and MRI, although metal artifacts degrade the latter two imaging methods. On ultrasound, the anterior, lateral, and posterior aspects of the joint should be interrogated carefully. ALTR occurs more often in posterior or lateral locations followed by anterior, which is typically related to the iliopsoas bursa. ${ }^{18}$ This corresponds to the commonly used surgical approaches. ${ }^{19}$ Interestingly, a pseudotumor has been reported in the urinary bladder, thought to be secondary to cement extrusion through acetabular defects. ${ }^{20}$ On ultrasound, ALTR may appear as an anechoic or hypoechoic fluid collection with little vascularity, which may demonstrate thick echogenic septations and marked synovial hypertrophy (-Fig. 2a). ${ }^{18}$ ALTRs are intimately related to the joint capsule and communicate with the hip joint (-Fig. 4a). ${ }^{9}$ ALTR appears on CT as a solid or cystic periarticular mass. CT is also useful in assessing periprosthetic bony changes. $^{21}$
Numerous studies have demonstrated the usefulness of MRI in detecting an ALTR. Basic sequences consist of axial T1-weighted and T2-weighted fast spin-echo and coronal T1-weighted sequences and short-tau inversion recovery sequences. Metallic artifact can be "directed" to optimize the region of interest by alternating phase and frequency encoding directions. Furthermore, metal artifact reduction sequences have made possible the use of MRI in patients with THAs. Metal artifact reduction sequences MRI was found to be superior to CT for the diagnosis and characterization of ALTR. ${ }^{21}$ MRI appearances suggestive of an ALTR consist of periprosthetic collections originating from the neck of the femoral component to the surrounding soft tissues. These are typically isointense to muscle on T1-weighted images (-Fig. 4c). On T2-weighted images, the fluid is usually hyperintense with a thick irregular pseudocapsule ( - Fig. 4b). The pseudocapsule is low signal intensity on T1-weighted and T2-weighted imaging 


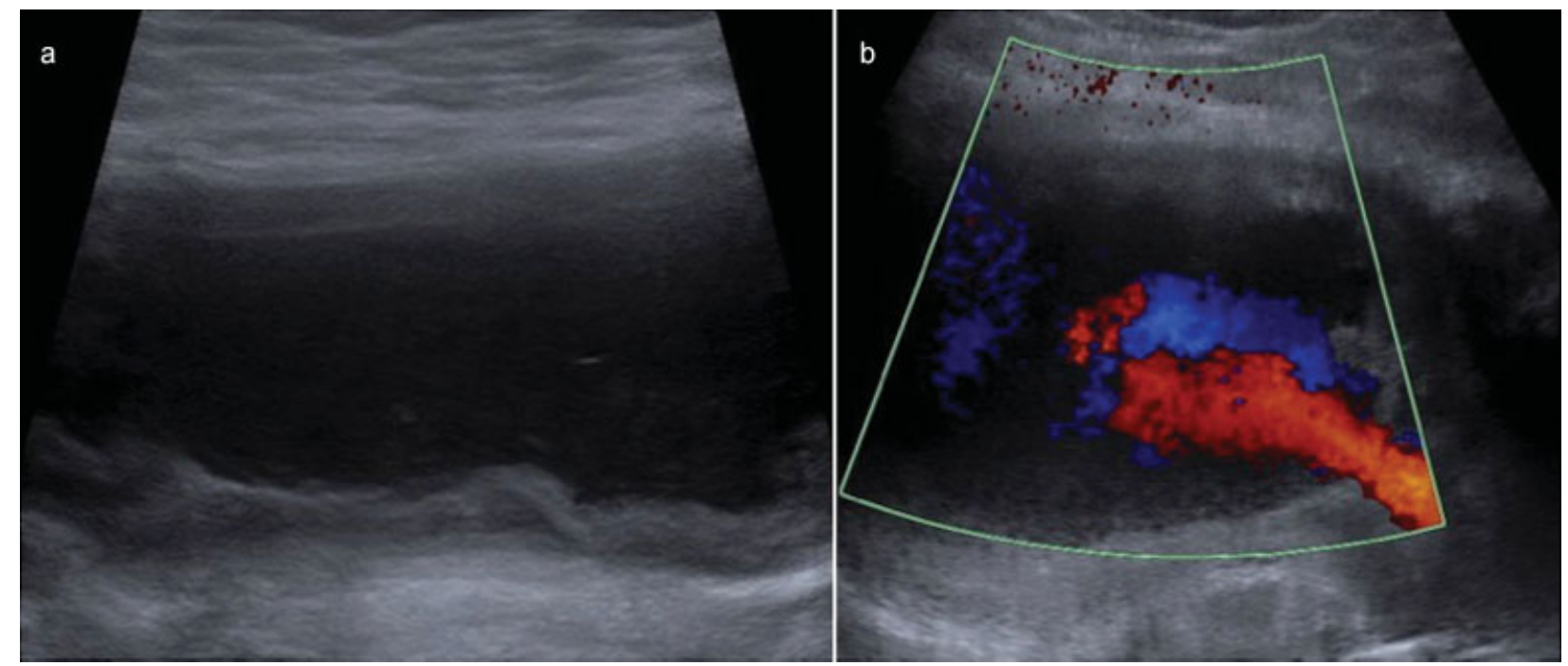

Fig. 3 Transverse ultrasound image more posterolaterally (a) demonstrates a second thick-walled cystic structure. Transverse Doppler image (b) demonstrates turbulent blood flow producing a yin yang pattern characteristic of a pseudoaneurysm.
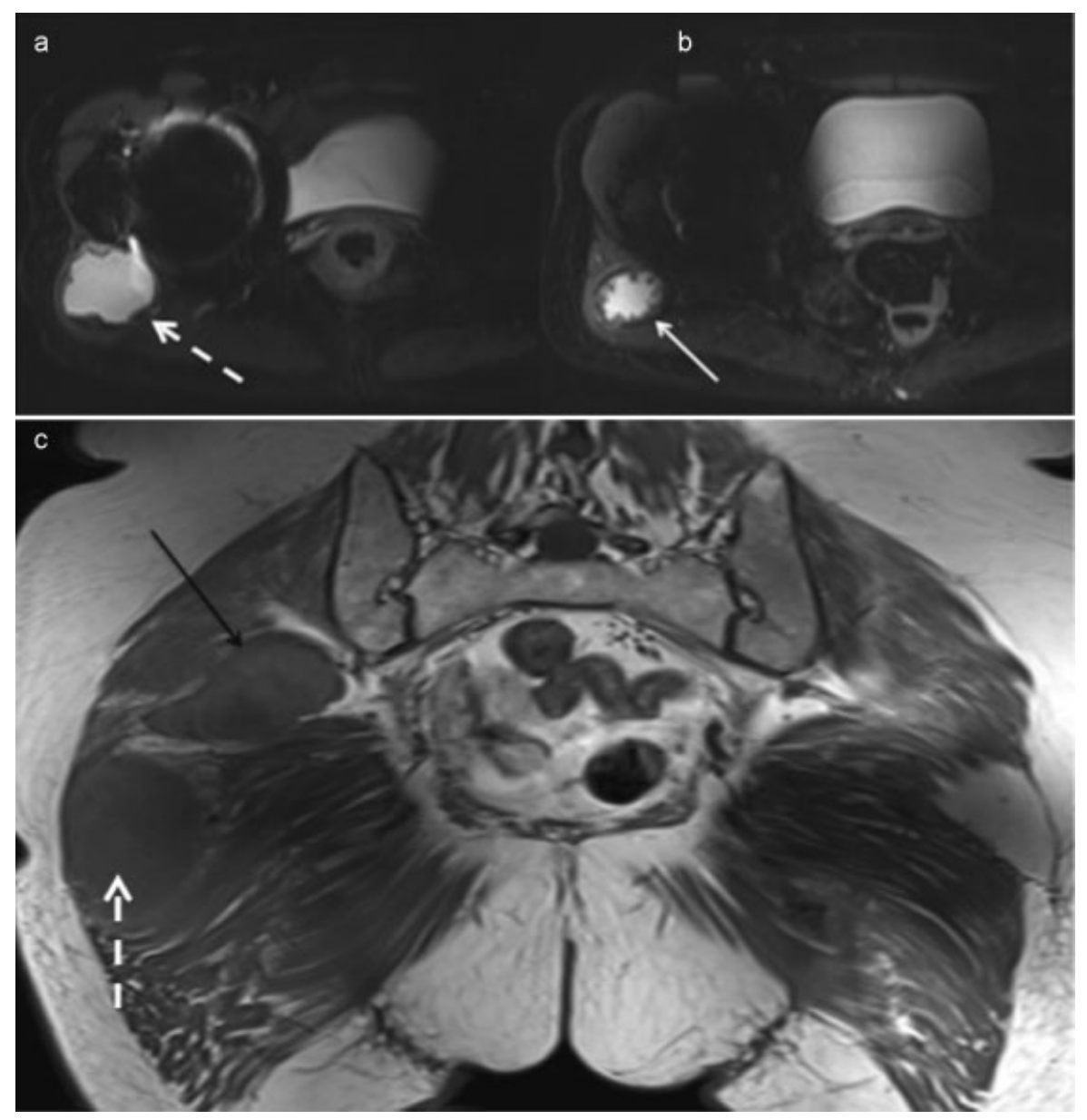

Fig. 4 Axial short tau inversion recovery magnetic resonance imaging (MRI) confirms a periarticular cystic structure related to the right hip joint (dashed white arrow in a and c) with a low signal pseudocapsule (solid white arrow in b) in keeping with an adverse local tissue reaction (ALTR). The ALTR (dashed white arrow) is isointense to skeletal muscle on coronal spin-echo T1 sequence (c). There is a second discrete lesion (solid black arrow in c) within the gluteal muscle with a rim that is isointense to muscle and intralesional hypointensity suggestive of turbulent flow in keeping with a pseudoaneurysm. 
caused by susceptibility artifact from the nanoparticles in the pseudocapsule. 9,17,21,22 $^{2}$

Management of pseudotumors is complex, and revision surgery may increase the risk of complications. Surgery tends to be more complex secondary to the soft tissue destruction. ${ }^{23}$ Outcomes for revision surgery for ALTR/pseudotumors are considerably worse than the outcome of other THA. ${ }^{24}$

\section{Pseudoaneurysm}

Vascular injuries, such as pseudoaneurysm formation, are a rare complication after THA. ${ }^{25}$ However, their potential must be considered due to the proximity of the vascular structures to the hip joint. ${ }^{26}$ Proposed intraoperative mechanisms include retractor injury, thermal injury from methyl methacrylate, or direct penetration from polymer or gouging during acetabular preparation. Postoperative mechanisms include acetabular component or cement migration leading to vascular erosion. ${ }^{27}$ The incidence of all vascular injuries post-THA is estimated between 0.08 and $0.67 \%$, with an average of 0.2 to $0.3 \%{ }^{28}$ Vascular injuries have been reported with both anterolateral or posterior surgical approaches with pseudoaneurysm formation of the profunda femoris and medial circumflex arteries. $^{29,30}$

Gluteal artery pseudoaneurysms represent less than $1 \%$ of all aneurysms with the majority of reported cases secondary to blunt or penetrating trauma or iatrogenic injury during injection or biopsy or due to acetabular component migration. $^{31,32}$ The superior gluteal artery is more commonly injured than the inferior gluteal artery. ${ }^{33}$

Presentation with a tender mass, which may be pulsatile, may occur weeks or months following THA. Other symptoms reported include hypotension, shock, limb edema, sciatic nerve palsy, and a bleeding wound fistula. ${ }^{26}$ Our case is unusual as the pseudoaneurysm was asymptomatic and found incidentally post-THA.
Imaging findings of a pseudoaneurysm include demonstration of a lesion contiguous with the parent artery with a patent or thrombosed lumen neck. Doppler ultrasound is the key to distinguish an ALTR from a pseudoaneurysm; a pseudoaneurysm will reveal arterial flow. The turbulent forward and backward flow often produces the characteristic yin yang sign on color flow (-Fig. 3b) and a to-and-fro pattern with pulsed Doppler imaging. ${ }^{34,35}$ Unenhanced CT may demonstrate a low-attenuation lesion with a neck arising from the parent artery. Attenuation within the pseudoaneurysm will depend on the composition of acute and chronic blood products. A CT angiogram will demonstrate contrast blush into the pseudoaneurysm (-Fig. 5). A communication with a parent artery may be visible, but like in our case cannot also be readily identified if the pseudoaneurysm arises from a small branch vessel. On MRI, arterial flow can manifest as a signal flow void on a noncontrast study with avid enhancement following administration of gadolinium. Concentric rings of thrombus in differing stages of evolution create heterogenous signal intensities on T1- and T2-weighted MRI, with a characteristic "blooming" artifact of hemosiderin on gradient-echo sequences as a result of increased magnetic susceptibility. ${ }^{36}$ Pulsation artifact may also be identified on MRI.

Several treatment strategies for pseudoaneurysm have been proposed, including direct suture, closure of the defect with a patch, resection of the aneurysm, thromboembolization, and endovascular repair.

\section{Conclusion}

THA is the second most common joint replacement surgery, ${ }^{1}$ and although complications of ALTR and pseudoaneurysm formation are rare entities on their own, we have presented a case where both have occurred unilaterally and concurrently. When a complex solid/cystic lesion is encountered in a

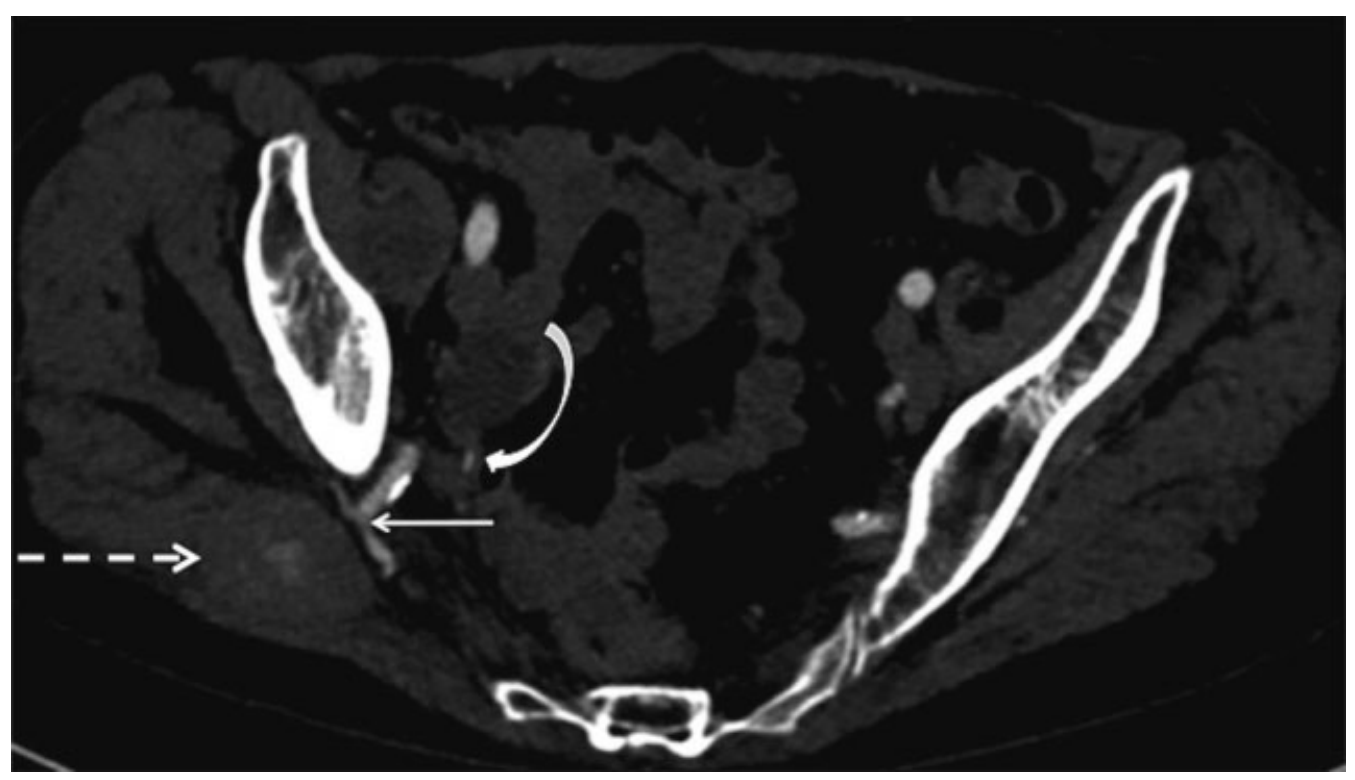

Fig. 5 Axial computed tomography angiogram demonstrates enhancement of the superior gluteal artery (straight white solid arrow), which is adjacent to a fusiform mass (dotted white arrow) within the gluteal muscles. The mass demonstrates internal contrast blush in keeping with a pseudoaneurysm. The curved white arrow indicates the inferior gluteal artery. 
patient with a THA, radiologists must ensure that the lesion is interrogated with color Doppler to confidently distinguish a pseudotumor from a pseudoaneurysm. This information is vital to the surgeon to avoid unexpected hemorrhage if revision joint replacement surgery is being contemplated.

\section{Conflict of Interest}

None declared.

\section{References}

1 National Joint Registry 8th Annual Report. Available at: http:// www.njrcentre.org.uk/NjrCentre/Portals/0/Documents/NJR 8th Annual Report 2011.pdf. Accessed May 18, 2015

2 Anderson H, Toms AP, Cahir JG, Goodwin RW, Wimhurst J, Nolan JF. Grading the severity of soft tissue changes associated with metalon-metal hip replacements: reliability of an MR grading system. Skeletal Radiol 2011;40(3):303-307

3 Chan FW, Bobyn JD, Medley JB, Krygier JJ, Tanzer M. The Otto Aufranc Award. Wear and lubrication of metal-on-metal hip implants. Clin Orthop Relat Res 1999;(369):10-24

4 Brodner W, Bitzan P, Meisinger V, Kaider A, Gottsauner-Wolf F, Kotz R. Elevated serum cobalt with metal-on-metal articulating surfaces. J Bone Joint Surg Br 1997;79(2):316-321

5 Daniel J, Ziaee H, Pradhan C, Pynsent PB, McMinn DJ. Blood and urine metal ion levels in young and active patients after Birmingham hip resurfacing arthroplasty: four-year results of a prospective longitudinal study. J Bone Joint Surg Br 2007;89(2):169-173

6 Wiley KF, Ding K, Stoner JA, Teague DC, Yousuf KM. Incidence of pseudotumor and acute lymphocytic vasculitis associated lesion (ALVAL) reactions in metal-on-metal hip articulations: a metaanalysis. J Arthroplasty 2013;28(7):1238-1245

7 Scaglione M, Fabbri L, Bianchi N, Dell'Omo D, Guido G. Metal-onmetal hip resurfacing: correlation between clinical and radiological assessment, metal ions and ultrasound findings. Musculoskelet Surg 2015;99(1):45-53

8 Medicines and Healthcare products Regulatory Agency (MRHA). Medical Device Alert: All metal-on-metal (MoM) hip replacements (MDA/2012/036). Available at: https://assets.publishing. service.gov.uk/media/5485abf6ed915d4c10000273/con155767. pdf. Accessed January 10, 2015

9 Fang CS, Harvie P, Gibbons CL, Whitwell D, Athanasou NA, Ostlere $\mathrm{S}$. The imaging spectrum of peri-articular inflammatory masses following metal-on-metal hip resurfacing. Skeletal Radiol 2008; 37(8):715-722

10 Glyn-Jones S, Pandit H, Kwon YM, Doll H, Gill HS, Murray DW. Risk factors for inflammatory pseudotumour formation following hip resurfacing. J Bone Joint Surg Br 2009;91(12):1566-1574

11 Pandit H, Glyn-Jones S, McLardy-Smith P, et al. Pseudotumours associated with metal-on-metal hip resurfacings. J Bone Joint Surg Br 2008;90(7):847-851

12 Kwon YM, Ostlere SJ, McLardy-Smith P, Athanasou NA, Gill HS, Murray DW. "Asymptomatic" pseudotumors after metal-on-metal hip resurfacing arthroplasty: prevalence and metal ion study. J Arthroplasty 2011;26(4):511-518

13 Campbell P, Ebramzadeh E, Nelson S, Takamura K, De Smet K, Amstutz HC. Histological features of pseudotumor-like tissues from metal-onmetal hips. Clin Orthop Relat Res 2010;468(9):2321-2327

14 Mahendra G, Pandit H, Kliskey K, Murray D, Gill HS, Athanasou N. Necrotic and inflammatory changes in metal-on-metal resurfacing hip arthroplasties. Acta Orthop 2009;80(6):653-659

15 Watters TS, Cardona DM, Menon KS, Vinson EN, Bolognesi MP, Dodd LG. Aseptic lymphocyte-dominated vasculitis-associated lesion: a clinicopathologic review of an underrecognized cause of prosthetic failure. Am J Clin Pathol 2010;134(6):886-893

16 Willert HG, Buchhorn GH, Fayyazi A, et al. Metal-on-metal bearings and hypersensitivity in patients with artificial hip joints. A clinical and histomorphological study. J Bone Joint Surg Am 2005;87(1):28-36

17 Thomas MS, Wimhurst JA, Nolan JF, Toms AP. Imaging metal-on-metal hip replacements: the Norwich experience. HSS J 2013;9(3):247-256

18 Douis H, Dunlop DJ, Pearson AM, O'Hara JN, James SL. The role of ultrasound in the assessment of post-operative complications following hip arthroplasty. Skeletal Radiol 2012;41(9):1035-1046

19 Palan J, Beard DJ, Murray DW, Andrew JG, Nolan J. Which approach for total hip arthroplasty: anterolateral or posterior? Clin Orthop Relat Res 2009;467(2):473-477

20 Park SJ, Lee HK, Yi BH, et al. Pseudotumour in the bladder as a complication of total hip replacement: ultrasonography, CT and MR findings. Br J Radiol 2007;80(954):e119-e121

21 Robinson E, Henckel J, Sabah S, Satchithananda K, Skinner J, Hart A. Cross-sectional imaging of metal-on-metal hip arthroplasties. Can we substitute MARS MRI with CT? Acta Orthop 2014;85(6): 577-584

22 Chang EY, McAnally JL, Van Horne JR, et al. Metal-on-metal total hip arthroplasty: do symptoms correlate with MR imaging findings? Radiology 2012;265(3):848-857

23 Quinn JR, Lee J, Schwarzkopf R. Inflammatory pseudotumor complicated by recurrent dislocations after revision total hip arthroplasty. Case Rep Orthop 2014;2014:792781

24 Grammatopoulos G, Pandit H, Kwon YM, et al. Hip resurfacings revised for inflammatory pseudotumour have a poor outcome. J Bone Joint Surg Br 2009;91(8):1019-1024

25 Nachbur B, Meyer RP, Verkkala K, Zürcher R. The mechanisms of severe arterial injury in surgery of the hip joint. Clin Orthop Relat Res 1979;(141):122-133

26 Giacchetto J, Gallagher JJ. False aneurysm of the common femoral artery secondary to migration of a threaded acetabular component. A case report and review of the literature. Clin Orthop Relat Res 1988;(231):91-96

27 Aust JC, Bredenberg CE, Murray DG. Mechanisms of arterial injuries associated with total hip replacement. Arch Surg 1981; 116(3):345-349

28 Riouallon G, Zilber S, Allain J. Common femoral artery intimal injury following total hip replacement. A case report and literature review. Orthop Traumatol Surg Res 2009;95(2):154-158

29 Thomas MS, O'Hara JN, Davies AM, James SL. Profunda femoris pseudoaneurysm following Birmingham hip resurfacing: an important differential diagnosis for a periarticular cystic mass. Skeletal Radiol 2012;41(7):853-856

30 Giannini S, Cadossi M, Chiarello E, Faldini C, Moroni A, Romagnoli M. Hip resurfacing arthroplasty: a series of 140 consecutive hips with a minimum five year follow-up. A clinical, radiological and histological analysis. Hip Int 2011;21(1):52-58

31 Vasseur MA, Doisy VC, Prat AG, Stankowiak C. Coil embolization of a gluteal false aneurysm in a patient with Marfan syndrome. J Vasc Surg 1998;27(1):177-179

32 Bakker KW, Gast LF. Retroperitoneal haemorrhage from the superior gluteal artery: a late complication of total hip arthroplasty. Clin Rheumatol 1990;9(2):249-253

33 Schorn B, Reitmeier F, Falk V, Oestmann JW, Dalichau H, Mohr FW. True aneurysm of the superior gluteal artery: case report and review of the literature. J Vasc Surg 1995;21(5):851-854

34 Lupattelli T. The yin-yang sign. Radiology 2006;238(3):1070-1071

35 Mahmoud MZ, Al-Saadi M, Abuderman A, et al. "To-and-fro" waveform in the diagnosis of arterial pseudoaneurysms. World J Radiol 2015;7(5):89-99

36 Kapoor BS, Haddad HL, Saddekni S, Lockhart ME. Diagnosis and management of pseudoaneurysms: an update. Curr Probl Diagn Radiol 2009;38(4):170-188 